\title{
ARTHUR RIMBAUD, Opere
}

\section{Ida Merello}

\section{OpenEdition Journals}

\section{Edizione digitale}

URL: https://journals.openedition.org/studifrancesi/32073

DOI: 10.4000/studifrancesi.32073

ISSN: 2427-5856

\section{Editore}

Rosenberg \& Sellier

\section{Edizione cartacea}

Data di pubblicazione: 1 août 2020

Paginazione: $427-428$

ISSN: 0039-2944

\section{Notizia bibliografica digitale}

Ida Merello, «ArThur rimbaud, Opere», Studi Francesi [Online], 191 (LXIV | II) | 2020, online dal 01

septembre 2020, consultato il 18 septembre 2021. URL: http://journals.openedition.org/studifrancesi/ 32073 ; DOI: https://doi.org/10.4000/studifrancesi.32073

Questo documento è stato generato automaticamente il 18 septembre 2021.

\section{(c) (i) (9)}

Studi Francesi è distribuita con Licenza Creative Commons Attribuzione - Non commerciale - Non opere derivate 4.0 Internazionale. 


\title{
ARTHUR RIMBAUD, Opere
}

\author{
Ida Merello
}

\section{NOTIZIA}

ARTHUR RIMBAUD, Opere, a cura di O. Bivort, traduzione di O. Tajani, con testo a fronte, Venezia, Marsilio, 2019, 849 pp.

1 Se le traduzioni di Rimbaud sono in Italia innumerevoli, più rare risultano le edizioni integrali, e soprattutto le edizioni critiche dell'opera. Dopo Ivos Margoni (1964), e tralasciando edizioni con apparato più leggero, si segnalano l'edizione Einaudi di Gian Piero Bona (1973), uscita l'anno dopo la Pléiade di Antoine Adam, di cui riprende le note (del resto, nel 1992, l'edizione italiana della Pléiade di Adam utilizza proprio le traduzioni di Bona, anche delle opere in prosa), e quella nei Meridiani di Diana Grange Fiori (1975) con l'introduzione di Bonnefoy. Dopo la traduzione di Adam i lavori si moltiplicano, ma l'edizione Marsilio di Bivort e Tajani si impone per un aspetto del tutto nuovo.

2 Il problema centrale di ogni edizione rimbaldiana è quello dell'organizzazione dei testi, dal momento che il solo volume curato da Rimbaud è stato Une saison en enfer, mentre buona parte delle poesie e delle Illuminations sono arrivate per mano di amici, trascritte e a volte rimaneggiate dagli stessi. La trascuratezza con cui Rimbaud aveva abbandonato i suoi lavori fa sì che ci siano continui ritrovamenti: malgrado il secolo $\mathrm{e}$ mezzo che ci separa, l'opera infatti continua a risultare in progress. Le prime edizioni, e lo stesso Adam, avevano cercato di organizzare il materiale in sezioni, per individuare una forma. La nuova edizione Pléiade di André Guyaux (2009), invece, ha suscitato scalpore per aver abbandonato ogni tentativo di composizione in nome di un unico criterio: quello della cronologia. Criterio assai arduo, visto che proprio la datazione dei testi, provenienti da fondi diversi, è stata oggetto di continua discussione. BIVORT prosegue in questa direzione, con qualche variante dovuta a una scansione cronologica più fitta. L'introduzione, molto limpida, si offre come guida anche per il lettore meno esperto, partendo da una citazione di Papini su "Lacerba" per presentare Rimbaud nella 
sua essenzialità esplosiva. "Tuttavia - ci ricorda comunque il prefatore-la sovrapposizione della vita e dell'opera non è inevitabile". È questo l'elemento essenziale per una lettura non condizionata dalla mitologia di un personaggio, pur se consapevole che in Rimbaud la funzione poetica, intesa come più intensa esperienza di vita, ha un potere incendiario e annichilente. Questo senza nulla togliere anche alla forza della tensione artistica e al lavoro di ricerca ritmica, linguistica, espressiva senza cui l'opera sarebbe impossibile.

Proprio questo è il punto di congiunzione con il lavoro di traduzione di Ornella TAJANI. Ispirandosi agli studi di Meschonnic sul ritmo, Tajani pone al centro delle scelte poetiche il mantenimento del tono generale e del ritmo, anche a scapito di una costanza metrica. Tono e ritmo rappresentano infatti il corpo del testo, insieme alle scelte lessicali e all'uso vagamente improprio di certe preposizioni, come "à" (quel fenomeno di "animazione delle preposizioni" che Leo Spitzer aveva già così bene individuato nel 1918 come caratteristico dell'epoca simbolista). Qui si vede l'importanza di un lavoro a quattro mani tra un critico esperto non solo della poesia rimbaldiana, ma anche storico della lingua, pronto a riconoscere le accezioni ottocentesche dei termini, e una traduttrice i cui fondamenti teorici si risolvono in flessibilità ritmica. «Il ritmo, scrive Tajani, non è semplicemente una generica musicalità, ma il movimento complessivo che l'autore dà al testo, impresso attraverso scelte non solo accentuali e prosodiche, ma anche lessicali e sintattiche». La traduzione appare molto originale, evita trappole di scansione e cadenze, cerca il recupero di una freschezza e intensità vicine al testo di partenza e spesso ci riesce.

4 Il volume è inoltre corredato da un imponente e originale apparato critico di più di duecento pagine, efficace nella sintesi critica e accompagnato da estesi rimandi bibliografici, oltre all'indicazione del manoscritto di provenienza per ogni singolo testo. 